\title{
UN MODELO EN CRISIS: EL CASO DE GRUPO NACIÓN EN COSTA RICA
}

\section{A MODEL IN CRISIS: THE CASE OF GRUPO NACIÓN IN COSTA RICA}

\author{
Lorenzo Ramírez Cardoza
}

Recibido: 05/08/2018 - Aceptado: 21/10/2018

\begin{abstract}
Resumen
Este artículo es un análisis preliminar de la situación financiera de Grupo Nación (Costa Rica) en el contexto de la crisis del modelo de negocios de la prensa. El análisis se realiza para el período 2005-2016 y se realiza sobre ingresos, utilidades netas, activos, pasivos, patrimonio, entre otros, a través del análisis horizontal y vertical y las razones financieras. El trabajo se realiza desde la perspectiva conceptual de los grupos de poder económico y las industrias culturales, por lo que Grupo Nación se comprende como un actor hegemónico con acciones económicas y políticas determinadas. El artículo sugiere que los rendimientos financieros de Grupo Nación son negativos: disminución de ingresos, pérdidas en las utilidades netas, bajo rendimiento de los activos, crecimiento de deudas, entre otros.
\end{abstract}

Palabras clave: Costa Rica, élites, medios de comunicación, análisis financiero, poder.

\begin{abstract}
This article is a preliminary analysis on the financial situation of Grupo Nación, within the context of crisis of contemporary printed media. This 2005 - 2016 analysis explores income, net profits, assets, liabilities, patrimony among others. It includes horizontal and vertical analysis as well as financial reasons. Literature about media conglomerates is the theoretical starting point of this study. Under this perspective the Grupo Nación is considered as a hegemonic actor within the Costa Rican media industry, which has had both economic and political long term repercutions. As conclusion, the article suggests that the financial performance of Grupo Nación is under red numbers: low income, losses on net utilities, low performance of assets and debt growth.
\end{abstract}

Keywords: Costa Rica, elites, media, financial analysis, power. 


\section{Introducción}

Este artículo es una primera aproximación al análisis de los estados financieros de la empresa Grupo Nación (en adelante GN) en el contexto de crisis del modelo de negocios de los medios de comunicación colectiva. ${ }^{1}$ El estudio se realizará para el período 2005-2016 y se hará sobre los recursos de la empresa y sus deudas. La evaluación financiera de la empresa girará en torno a su actividad productiva más directa (producir para generar ganancias), a través del comportamiento y rendimiento de sus ingresos, activos, utilidades netas, patrimonio, entre otros, a lo largo del tiempo. Es posible contar con información financiera de GN porque al participar en la Bolsa de Valores costarricense, el Grupo está obligado a presentar públicamente sus estados financieros, los cuales se encuentran en la página web de la empresa (www.gruponacion.co.cr), o bien, en la página web de la Bolsa de Valores de Costa Rica (www.bolsacr.com).

GN es una empresa mediática costarricense cuyos mayores accionistas son la familia Jiménez, constituida por tres generaciones e históricamente relacionada con diversas actividades económicas. En el pasado se vincularon a la producción de café, caña de azúcar y arroz; de manera reciente, al sector turístico, inmobiliario, de comercialización y producción de eventos y a la importación y exportación de vehículos de lujo (Fournier; Robles y Voorend). Como empresa mediática realiza actividades productivas para generar ganancias, por ejemplo, vender medios de comunicación impresos y espacio publicitario dentro de estos, lo cual realiza, principalmente, a través de sus periódicos La Nación y La Teja.

En el contexto de los grupos de comunicación centroamericanos, GN tiene una posición hegemónica en el sector. Históricamente ha contado con el mayor tiraje de impresos y el mayor grado de concentración de los ingresos publicitarios del mercado (Chamorro; Mastrini y Becerra). Además, el Grupo se regionalizó y tuvo participación empresarial con Distribuidora de Papeles y Cartulinas en Nicaragua; con Comunicación Integral El Salvador S. A., en El Salvador; con ABC de Honduras, en Honduras; con Corporación de Noticias S. A., en Guatemala; y en Panamá con Prensa Económica Panamá y Bloque Activo Centroamericano (La Nación S. A. y Subsidiarias, 2009; Robles y Voorend). En la actualidad, GN mermó sus negocios en la región. Ahora, además de Costa Rica, solo cuenta con participación en Panamá a través de la posesión de una reducida cantidad de acciones sobre Corporación La Prensa S. A., propietaria de los medios La Prensa, Mi Diario, entre otros suplementos, y con la subsidiaria inmobiliaria Desarrollos Los Olivos S. A. (La Nación S. A y Subsidiarias, 2016).

GN se comprende desde la perspectiva de los grupos de poder económico (Segovia; Robles y Voorend; Robles) y desde las industrias culturales (Adorno y Horkheimer; Mastrini). Como grupo de poder económico, GN es un actor cuyo peso económico le permite acciones políticas en las relaciones culturales de la región, fundamentalmente, en Costa Rica. Con el periódico La Nación, este actor político se constituye como el portavoz del conjunto de los costarricenses, es decir, como el portador del punto de 
vista de "la nación" (Sandoval), además, reúne intereses empresariales nacionales y transnacionales (Martín; Sandoval; Fournier; Robles y Voorend). Con el periódico La Teja evita tematizar contenido político, con lo cual dificulta la generación de explicaciones sobre el acontecer (Sandoval; Ramírez). Desde la perspectiva de las industrias culturales, el modo de producción de GN se concibe como industrial. Lo anterior implica producir noticias en serie, de manera estándar, con división del trabajo, en torno a la lógica de generar excedentes económicos y, por tanto, bajo la relación ingresos-costos. Además, se concibe dentro de un sector económico determinado con sus respectivas condiciones macroeconómicas, diversos actores y desarrollos técnicos y tecnológicos propios, o de otras industrias, con los cuales se relaciona.

Con el análisis preliminar de los estados financieros de GN, este trabajo pretende reflexionar alrededor de la situación financiera de un grupo de poder hegemónico centroamericano, en el contexto de la crisis del modelo de negocios de las industrias culturales, como se desarrollará más adelante. En lo que respecta a la organización del artículo, este está dividido en cinco apartados. El primer apartado explora la perspectiva sobre la crisis de los medios de comunicación colectiva a partir de algunos autores y menciona de manera breve el caso para la industria de impresos costarricense. En el segundo apartado se explican las consideraciones metodológicas para realizar la aproximación al análisis financiero. El tercero corresponde al análisis de los estados financieros de GN, el cual parte de una breve contextualización de la situación económica en la cual opera la empresa. Posteriormente, se exploran las cuentas del estado de resultados y el balance general con razones financieras. Finalmente, el último apartado es un balance del artículo, en el cual se sugiere que los rendimientos financieros de GN tienden a disminuir en el período de estudio.

\section{Un modelo en crisis}

En algunos países del mundo, como Estados Unidos de América (en adelante EE. UU.), el Reino Unido, México, entre otros, se produce un deterioro del modelo de negocios de los medios de comunicación colectiva, tanto en impresos, canales de televisión y radio (Martínez; Siles y Boczkowski; Carazo; Villamil, 2016, 2017). Este modelo, basado en la venta de espacio publicitario y el nivel de audiencia para producir excedentes económicos, expresa reducciones significativas. Para la industria de medios de comunicación colectiva, el deterioro del modelo se expresa fundamentalmente, pero no de manera exclusiva, en la disminución constante de ingresos por venta de espacio publicitario. En el caso de los medios de comunicación impresos, que interesa a este artículo, además de la reducción de ingresos publicitarios, se percibe una disminución de los ingresos recibidos por circulación (venta del medio). Lo que ha tenido como consecuencia el cierre total de periódicos, el traslado definitivo de la versión impresa de otros a una versión digital, recorte de personal y transformaciones en los contenidos de los medios (Martínez; Carazo). 
El carácter o modo de ser de la crisis de los medios de comunicación colectiva varía según los países, la época histórica y la cultural; no obstante, es posible señalar de manera general algunas de las fuentes o razones en determinadas culturas. Siles y Boczkowski sugieren tres razones para la situación crítica de las industrias culturales: una económica, otra tecnológica y una social. La razón económica se basa en la dependencia del modelo de negocios de generar la mayor cantidad de sus ingresos a partir de la venta de espacio publicitario, un excesivo afán de lucro, incluso en detrimento de los contenidos de los medios, y a la crisis económica capitalista que, como sugiere Martínez y Ferris, ha acentuado la de los medios. La fuente tecnológica a la crisis se vincula con los avances en dispositivos electrónicos e internet y los hábitos de consumo de las audiencias. En algunas culturas, en las cuales la penetración de internet es profunda, los hábitos para informarse han cambiado. Quienes antes se informaban en medios impresos, ahora lo hacen en Internet. Esto se debe a que, en internet, la información se suministra en tiempo real y les permite a las audiencias un ambiente de alta elección (Thompson; Pior), lo cual significa tener a disposición una diversidad de opciones para informarse en tiempo real, a diferencia de los medios no vinculados a internet, los cuales tienen, por su carácter estático, una reducida gama de alternativas.

Los dos aspectos anteriores sitúan la crisis en el modelo de negocios de las industrias culturales. En el contexto de los medios impresos, si las personas tienden a leer más en digital y si publicitar en digital le sale más barato a los anunciantes, entonces, el costo por millar en el impreso se incrementa, toda vez que la publicidad llega a menos lectores. La venta de publicidad se convierte en la principal fuente de ingresos de los medios, esto último resulta crucial para su modelo de negocios, pues los anunciantes trasladarán su pauta publicitaria a internet, donde tendrá mayor cobertura y un costo menor; en consecuencia, se reduce el principal ingreso de la industria de impresos. Esta situación también ocurre en otras industrias culturales, como la televisión (abierta o de pago) y la radio, entre otras, pero de manera significativa en la industria de impresos (Martínez; Ferris). También, los ritmos de disminución difieren según las culturas. En países anglosajones, como EE. UU. y Reino Unido, el ritmo del deterioro de sus ingresos es mucho mayor que en Japón y Rusia, por ejemplo. En contraste, dicho deterioro no se registra en China (Martínez; Ferris). En América Latina, hasta hace poco se constata que medios de comunicación colectiva en Brasil, Costa Rica y México ven reducidos sus ingresos (Carazo; Manghi; Villamil, 2016, 2017), pero, en el marco de la región, aún no se tiene una dimensión concreta de la situación crítica de la industria.

En lo que respecta a la fuente social de la crisis, para el caso de países anglosajones, Siles y Boczkowski la asocian con una pérdida de credibilidad hacia los medios, las noticias y los periodistas por parte de la población. Lo anterior porque, según los autores, algunos medios se han vinculado con casos de corrupción, lo cual ha mermado su legitimidad. También, con la diversidad de informaciones en internet, las audiencias tienen mayor posibilidad de contrastar la información suministrada 
por los medios, lo cual les permite determinar de manera relativa la posición de los medios frente algunos temas y, a partir de ello, según los intereses de las audiencias, posicionarse a favor o en contra de los medios. Para el caso de Centroamérica, y América Latina en general, esta causa de la crisis podría no existir o estar en período de gestación. Para el caso centroamericano, en el inicio de siglo XXI, Chamorro constata que los medios de comunicación colectiva tienen credibilidad. De igual forma, en una investigación reciente sobre las demandas de jóvenes centroamericanos de barrios populares, Sandoval (2018) encuentra que los jóvenes encuestados exhiben un alto grado de confianza hacia los medios de comunicación colectiva.

Ahora, a modo de contexto, para el caso de Costa Rica, se expondrá de manera breve el estado de la penetración de internet y su nivel de audiencia o consumo; así como el comportamiento de los ingresos por publicidad de los cuatro periódicos impresos vigentes hasta el año 2016 y el nivel general de audiencia de la industria de impresos. En Costa Rica, como se constata de las estimaciones del INEC, la penetración de internet en la población es profunda. Para el año 2016, se registra que el acceso de la población a dicha tecnología es través de computadoras y celular; de las personas que habitan por vivienda, el $46.57 \%$ tiene acceso a computadora y el $95.70 \%$ a celular. De manera fundamental, el acceso a internet de la población costarricense ha sido a través de internet móvil vía celular. Según el informe 2016 de la Superintendencia de Telecomunicaciones (SUTEL), para el año 2012 se registraron 2670208 suscriptores a internet móvil, mientras que para el año 2015, la cifra ascendió a 4861898 suscriptores, un aumento del $82 \%$. Si para el 2012, 57 de cada 100 tuvieron acceso a internet móvil, para el 2015, 101 de cada 100 personas poseen dicha tecnología (SUTEL).

En este contexto de alta penetración de internet en la población costarricense, es importante constatar cuál es el nivel de audiencia de periódicos impresos e internet en la industria, información que se presenta la Tabla 1.

Tabla 1

AUDIENCIAS DE PERIÓDICOS E INTERNET PARA COSTA RICA POR AÑO, 2011-2016 (EN PORCENTAJES)

\begin{tabular}{ccccccc}
\hline Años $^{*}$ & 2011 & 2012 & 2013 & 2014 & 2015 & 2016 \\
\hline Periódicos (últimos 30 días) & 88 & 78 & 75 & 66 & 43 & 44 \\
Internet (últimos 30 días) & 43 & 50 & 72 & 76 & 84 & 86 \\
\hline
\end{tabular}

Fuente: Elaboración propia a partir de Kantar Ibope Media. *Los años representan la audiencia estimada a los meses de setiembre, octubre y noviembre. 
La Tabla 1 exhibe una tendencia a la disminución del porcentaje de audiencia para los periódicos impresos; en el período 2011-2016, se observa una reducción del $44 \%$. En cambio, los datos muestran un incremento en la audiencia de internet de alrededor de $43 \%$. Prácticamente, en la medida que aumenta el consumo de internet, disminuye el de impresos. Para el caso costarricense, los datos anteriores pueden sugerir cambios en los hábitos de información de la población: la ciudadanía podría informarse más en medios digitales que en impresos.

El comportamiento de los ingresos recibidos por la venta de espacio publicitario en la industria de impresos se puede observar en la Figura 1. Asimismo, se percibe que los ingresos por publicidad tienen 2 descensos en su magnitud (líneas rojas verticales). El primero de estos solo ocurre en el año 2009 y para 3 de los 4 medios. La Nación, La Teja (ambos de GN) y La República decrecen dicho año; en cambio, Diario Extra crece. Este decrecimiento en la magnitud de los ingresos publicitarios sucede el mismo año en el cual la economía de Costa Rica, al igual que la economía de la mayoría de países de la región, tuvo una caída en su producción que desencadenó en una situación económica crítica para los años posteriores al 2009, como se comentará más adelante. Si la producción es negativa, es posible sugerir que los anunciantes dejaran de pautar en esas condiciones.

Figura 1

TASA DE VARIACIÓN POR AÑO DE LOS INGRESOS PUBLICITARIOS EN MEDIOS IMPRESOS DE COSTA RICA, 2007-2016 (EN PORCENTAJES*)

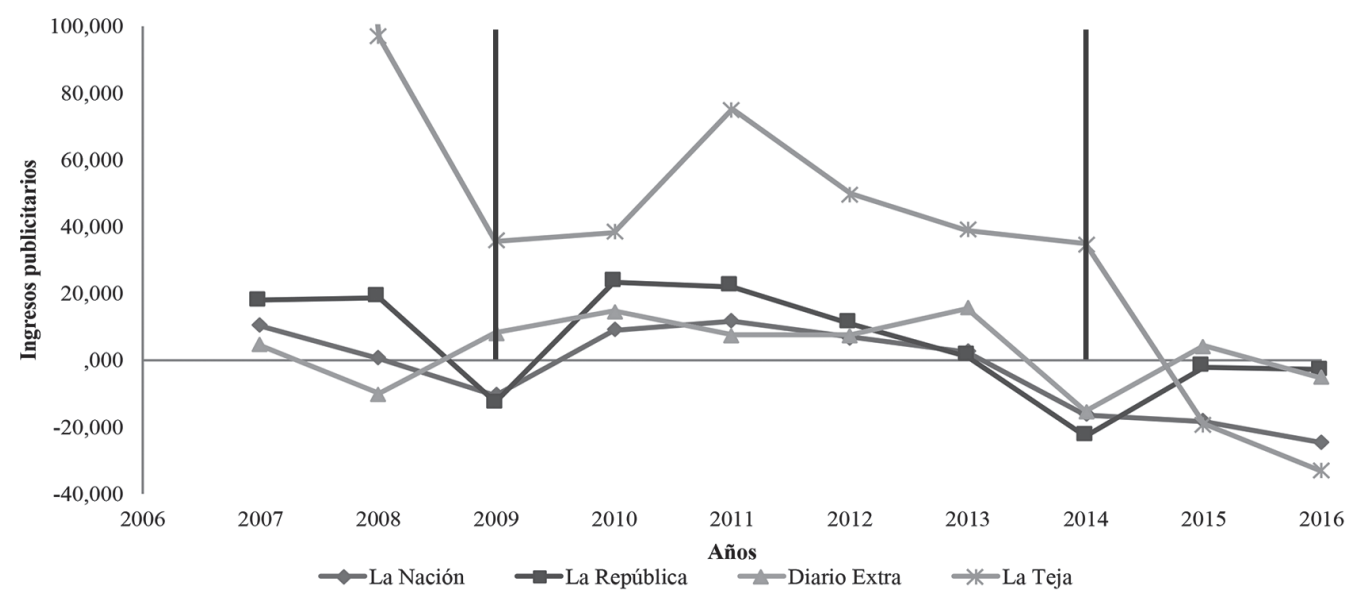

Fuente: Elaboración propia a partir de Kantar Ibope Media. *Variación con cifras deflactadas.

El segundo descenso en la magnitud de los ingresos publicitarios se observa durante tres años consecutivos a partir del 2014 y para 3 de los 4 medios que componen el mercado de impresos costarricense: La Nación, La República y Diario Extra (este último 
tiene un leve repunte en el 2015, el cual no se sostiene durante el 2016). Los ingresos por publicidad del periódico La Teja disminuyen durante el año 2015 y 2016. En el período de análisis, 2 años muestran la caída en la magnitud de los ingresos por publicidad para todos los medios impresos de la industria. Además de estos decrecimientos, en la Figura 1, para el período 2010-2013 se observa cómo la tasa de variación de los ingresos de todos los medios impresos tiende a crecer cada vez menos, lo cual sugiere aumentos en su magnitud cada vez más leves conforme pasan los años. Lo anterior indica que los decrecimientos en los ingresos por publicidad son antecedidos por aumentos cada vez menores de dichos ingresos.

Como se ha valorado, la situación crítica en el modelo de negocios de las industrias culturales expresa una reducción en el nivel de audiencia y los ingresos por venta de espacio publicitario, entre otras manifestaciones. Los datos explorados para el caso de la industria de impresos costarricenses exhiben un comportamiento similar: en el período de análisis, el porcentaje de audiencia de los impresos baja de manera significativa y los ingresos por publicidad empiezan a mostrar un deterioro, sobre todo a partir del año 2014. En este contexto, Carazo constata varios cambios en la industria de impresos, entre otras transformaciones en las diversas industrias costarricenses, como el traslado de periódicos de versión impresa a solo versión digital, y, para el caso de GN, el despido de 156 trabajadores y el cierre total de periódicos y revistas. Todo lo anterior puede sugerir el establecimiento de una crisis en el modelo de negocios del mercado de medios impresos y, en particular, para el caso de GN.

\section{Hacia el análisis de los estados financieros de Grupo Nación}

Ahora se analizará la situación financiera de GN del año 2005 al 2016. Como se mencionó en la introducción, los aspectos a analizar son los recursos y deudas de la empresa. También, se quiere evaluar la actividad productiva, es decir, el comprar, vender y generar ingresos y utilidades. Para cumplir con este análisis, se estudiarán algunas cuentas del balance general y estado de resultados, tales como ingresos, costos, inventario, utilidades netas, activos, pasivos y patrimonio, entre otros. Además, se usará el análisis horizontal y vertical, así como algunas razones financieras. Estos instrumentos se eligen porque permiten una evaluación interna de la actividad productiva de la empresa, es decir, el cómo se gestiona, lo cual, en un contexto de crisis, es importante determinar. Por ser este un análisis preliminar, se excluye de la evaluación la relación de GN con sus proveedores y el Mercado de Valores de Costa Rica. A continuación, se explicará la metodología y los conceptos necesarios para realizar el análisis financiero.

El balance general contiene información sobre los recursos que las empresas tienen y deben a una fecha determinada (Meoño y Jara). En el balance se encuentran los activos, es decir, la manera en la cual la empresa tiene invertidos sus recursos; los pasivos y el patrimonio, los cuales indican de dónde obtuvo la empresa sus recursos. 
Los pasivos indican que los recursos se obtuvieron a través de deuda y el patrimonio por medio de recursos aportados por los dueños o accionistas (Meoño y Jara). En cambio, el estado de resultados proporciona información sobre el estado de la actividad productiva de las empresas a una fecha determinada. En el estado de resultados están las cuentas de costos y utilidades, entre otros (Meoño y Jara).

El análisis horizontal es sobre el tiempo; se comparan dos períodos de tiempo a través de tasas de variación. El análisis vertical muestra la composición de la cuenta que se quiere analizar en un período específico, esto quiere decir que se realizan proporciones (numerador/denominador x 100) sobre las cuentas bajo análisis (Meoño y Jara). Una razón financiera es un número índice que relaciona entre sí, a través de una división, dos elementos diferentes de información financiera (Wong; Meoño y Jara). Con las razones financieras se pueden comparar las cuentas del estado de resultados y del balance general. Dichas razones se clasifican de acuerdo con el elemento de la empresa que se quiere analizar. Existen de liquidez, actividad, de deuda, entre otras. A continuación, se presentan las razones financieras que se utilizarán para este análisis.

\section{Razones de liquidez}

Según Wong y Meoño y Jara, las razones de liquidez señalan la capacidad de la empresa para resolver sus obligaciones o deudas a corto plazo, con recursos propios. Cuando la empresa cubre sus deudas con sus recursos tiene solvencia o liquidez. Las razones de liquidez que se utilizan en este análisis son la razón circulante (en adelante $\mathrm{RC}$ ) y la razón prueba ácida o de liquidez inmediata (en adelante RPA). La RC muestra la capacidad de la empresa para cubrir sus pasivos circulantes con sus activos circulantes en el corto plazo. La RPA muestra una liquidez más inmediata, esto por eliminar de la operación aritmética los inventarios, que es el activo que dura más en convertirse en efectivo. Así las cosas, ambas razones muestran la liquidez o solvencia, la RPA, al eliminar el inventario, indica una capacidad "más liquida". La fórmula RC es:

$$
R C=\frac{\text { Activo circulante }}{\text { Pasivo circulante }}=\text { en número de veces }
$$

La interpretación RC indica que, por cada colón de deuda que tiene la empresa, tiene " $x$ " colones de activos 0 , también, los activos son tantas "veces" los pasivos. Cuanto más grande es la razón, mejor para la empresa, porque indica que los recursos en efectivo que tiene pueden cubrir sus deudas. El parámetro idóneo es 2.5 veces (Wong). La fórmula RPA se expresa como: 


$$
R P A=\frac{\text { Activo circulante }- \text { inventario }}{\text { Pasivo circulante }}=\text { en número de veces }
$$

La interpretación de la RPA es la misma que la de la RC; sin embargo, el parámetro idóneo cambia, es de 1.5 veces (Wong).

\section{Razones de actividad}

Las razones de actividad muestran la efectividad con la cual la empresa administra sus activos o sus recursos en el largo plazo. Existen razones de actividad de diversos tipos, tales como la rotación de inventarios, período medio de cobro, período medio de pago, entre otras (Meoño y Jara). La razón de actividad que se utilizará es la rotación de inventarios (en adelante RI), la cual analiza la política de ventas de una empresa a partir de la "salida" de su inventario (Wong). La política de ventas de una empresa es la actividad productiva, en la cual compra, vende y obtiene ingresos y utilidades (recursos propios).

Una RI alta indica que la empresa cumple con su actividad productiva en un período de tiempo corto y, por lo tanto, genera recursos propios con rapidez, es decir, es eficiente. Entonces, cuanto más alta la razón, más rápido gira su inventario y por ello más veces al año cumple su actividad productiva. Lo anteriiior puede indicar una correcta administración de los activos. La fórmula de la RI es:

$$
R I=\frac{\text { Costos de venta }}{\text { inventarios }}=\text { en número de veces }
$$

La interpretación de la RI indica que la empresa rota su inventario o cumple actividad productiva " $x$ " veces al año. También, la RI puede calcularse en días al año. De la siguiente manera:

$$
R I \text { días }=\frac{365}{R I}=\text { en número de veces }
$$

Cuanto menor sea la RI en días, la empresa cumple en un menor tiempo, medido en días, la actividad productiva, lo cual es favorable.

\section{Razón de endeudamiento}

Las razones de deuda revelan el grado en el cual la empresa se ha financiado con deudas, o sea, indican su compromiso con terceros (Wong; Meoño y Jara). 
Las razones de deuda que se utilizarán son: razón endeudamiento corriente (en adelante REC), razón pasivo-patrimonio (en adelante RPP) y razón endeudamiento total (en adelante RET). La REC analiza el corto plazo, la RPP y RET el largo plazo. La REC indica el porcentaje de activos que se financian con deuda en el corto plazo. Cuanto más pequeño el porcentaje, mejor para una empresa (Wong). La fórmula es la siguiente:

$$
\text { REC }=\frac{\text { Pasivo corriente }}{\text { Activos totales }} * 100=\%
$$

La interpretación REC indica que la cantidad de activos financiados con deuda en el corto plazo es " $x$ " porcentaje.

La RPP relaciona las deudas con los recursos aportados por los dueños de la empresa. Esta razón señala la cantidad de colones de patrimonio, por cada colón de deuda o las veces que los pasivos cubren el patrimonio. Cuanto más baja sea esta razón, la empresa tiene mayores posibilidades de solventar eventuales pérdidas en las utilidades o pérdida total (cierre de la empresa), es decir, cuanto más baja, mayor margen de protección para una empresa (Wong; Meoño y Jara). La fórmula es la siguiente:

$$
R P P=\frac{\text { Pasivo total }}{\text { Patrimonio }}=\text { en número de veces }
$$

La interpretación RPP expresa que, por cada colón de patrimonio, existen " $x$ " colones de deuda o el pasivo es tantas "veces" el patrimonio.

Por último, la RET relaciona todo lo que la empresa tiene para generar recursos y el financiamiento con el cual lo ha conseguido, es decir, indica el porcentaje de activos totales que se financian con deuda. Cuanto más bajo el porcentaje, es mejor para la empresa (Wong; Meoño y Jara). La fórmula de la RET es:

$$
R E T=\frac{\text { Activos totales }}{\text { Pasivos totales }} * 100=\%
$$

La interpretación RET expresa que la cantidad de activos totales financiados con deuda son " $x$ " porciento. La Tabla 2 muestra un parámetro para interpretar dicha razón. 
Tabla 2

PARÁMETROS PARA EVALUAR LA RAZÓN ENDEUDAMIENTO TOTAL

\begin{tabular}{cc}
\hline Parámetro & Evaluación \\
\hline De $00 \%$ a $35 \%:$ & Endeudamiento Normal \\
De $36 \%$ a $55 \%:$ & Endeudamiento Sostenible \\
Más del $56 \%:$ & Exceso de Deudas \\
\hline
\end{tabular}

Fuente: Elaboración propia a partir de Wong.

\section{Razones de rentabilidad}

Estas razones muestran los resultados combinados de la gestión de liquidez, la administración de los activos y las deudas (Meoño y Jara). Es, por así decirlo, un resumen de la actividad productiva que permite identificar su rendimiento (Wong). Existen diversas razones de rentabilidad, aquí se utilizarán: margen de utilidad neta (en adelante $\mathrm{MUN}$ ), rotación de activos totales (en adelante RAT) y rendimiento sobre la inversión (en delante RSI). El MUN muestra el margen de ingresos que se apropia la empresa después de deducir costos de ventas, gastos administrativos, intereses e impuestos (Meoño y Jara). La fórmula es la siguiente:

$$
\text { MUN }=\frac{\text { utilidad neta }}{\text { ventas } \text { o ingrestos totales }} * 100=\%
$$

La interpretación MUN indica que la utilidad neta de la empresa representa el " $x$ " porcentaje de los ingresos o la empresa se apropia del " $x$ " porcentaje de los ingresos producidos. La Tabla 3 muestra un parámetro de interpretación.

Tabla 3

PARÁMETROS PARA INTERPRETAR EL MARGEN DE UTILIDAD NETA

\begin{tabular}{cc}
\hline Parámetros & Interpretación \\
\hline Menos de $5.00 \%$ & Rentabilidad Baja \\
De $6.00 \%$ a $10.00 \%$ & Rentabilidad Media (aceptable) \\
Más del $10.00 \%$ & Alta Rentabilidad \\
\hline
\end{tabular}

Fuente: Elaboración propia a partir de Wong. 
La RAT relaciona los ingresos totales de la empresa con sus activos. La relación es una división (Wong), esta relación proporciona información sobre la cantidad de ingresos que proporcionan los activos. Cuanto más grande la RAT, más ingresos generan los activos invertidos. La fórmula es la siguiente:

$$
R A T=\frac{\text { ventas } o \text { ingresos totales }}{\text { activos totales }}=\text { en número de veces }
$$

La RAT significa que por cado colón invertido en activos, la empresa genera " $\mathrm{x}$ " colones de ingresos o los ingresos son tantas veces los activos.

Por último, el RSI indica la capacidad de generar utilidades por parte de los activos invertidos por la empresa (Meoño y Jara). Según Wong, el RSI debe ser como mínimo igual o mayor que la tasa básica pasiva del mercado. Si la RSI es menor a la tasa básica, la empresa obtendría mejores rendimientos si sus activos estuvieran en un banco. En este sentido, la tasa básica es lo que la economía liberal conoce como "costo de oportunidad", es decir, lo que deja de percibir la empresa por realizar sus operaciones. La fórmula es la siguiente:

$$
\text { RSI }=\frac{\text { utilidad neta }}{\text { activos totales }} * 100=\%
$$

La RSI significa que la utilidad neta es un " $x$ " porciento de los activos totales. Cuanto más alta, mayor rendimiento generan los activos de la empresa.

\section{Análisis financiero de Grupo Nación}

Para realizar un análisis de los estados financieros de cualquier empresa es importante evaluar el contexto económico en el cual se desenvuelve. Por ello, se hará un análisis breve de la economía de Costa Rica a partir de la producción o la riqueza medida por el Producto Interno Bruto (en adelante PIB) y la inflación medida por medio el Índice de Precios al Consumidor (en adelante IPC), con información de la página web del Banco Central de Costa Rica (www.bccr.fi.cr); y se evaluará un aspecto del mercado de trabajo, la tasa de desempleo, con información de la página web del Instituto Nacional de Estadísticas y Censos (INEC) (www.inec.go.cr). La Figura 2 contiene información sobre el PIB, el cual representa la riqueza producida en el país a través del dinero (la producción), para lo que va del presente siglo. Este se evaluará a continuación. 
Figura 2

VARIACIÓN ANUAL Y ANUAL PROMEDIO DEL PRODUCTO INTERNO BRUTO PARA CR, DEL AÑO 2000 AL 2016 (EN PORCENTAJES)

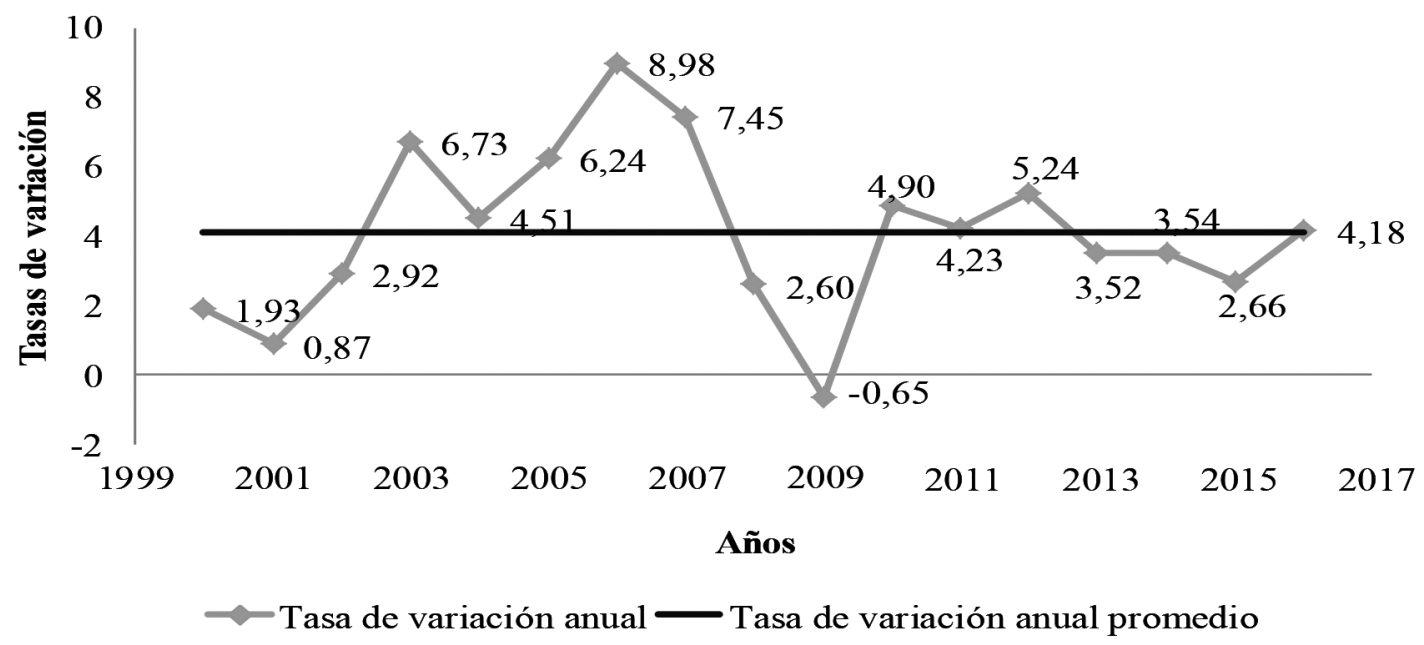

Fuente: Elaboración propia a partir de datos del BCR.

Como se observa en la Figura 2, para lo que va del siglo XXI, el crecimiento anual promedio de la economía nacional es de 4.18 \% (línea roja). Esta cifra es indicador de las capacidades medias de producción, es posible advertir que en la mayor parte de los años comprendidos entre el año 2000 y el año 2008, la economía nacional crece por arriba de sus capacidades medias, lo cual es positivo. Los mejores crecimientos oscilaron entre el $6.5 \%$ y el $8.8 \%$. En cuanto al desempleo, entre el año 2001 y el año 2008, es posible constatar de las estimaciones del INEC una tasa de desempleo anual promedio de aproximadamente un $6.5 \%$.

En cambio, después del año 2009 se observa otro comportamiento del PIB. Para el año 2009, la economía nacional decreció $0.65 \%$, es decir, hubo una caída en la magnitud de la producción. Después de ese decrecimiento, la economía mantiene un ritmo de producción menor al de sus capacidades medias o muy cerca de esta, crece al redor de un $4 \%$ o menos. Del año 2008 al 2016, el crecimiento más alto es de un $5.24 \%$, lejos de los mejores crecimientos previos al año 2009, lo cual sugiere un estado negativo de la economía para casi 10 años. En lo que respecta al mercado de trabajo, la tasa de desempleo del año 2009 al 2016 promedia un $9.5 \%$ anual; porcentaje superior a la tasa anterior al año 2009.

Hasta ahora se ha valorado brevemente el "sector real" de las relaciones económicas o productivas. Con la Figura 3 se tiene la intención de comentar un aspecto del "sector monetario", el cual remite a la inflación medida por el IPC. 
Figura 3

VARIACIÓN ACUMULADA DE LA INFLACIÓN MEDIDA POR EL IPC, PARA COSTA RICA, DEL 2000 AL 2016 (EN PORCENTAJES)

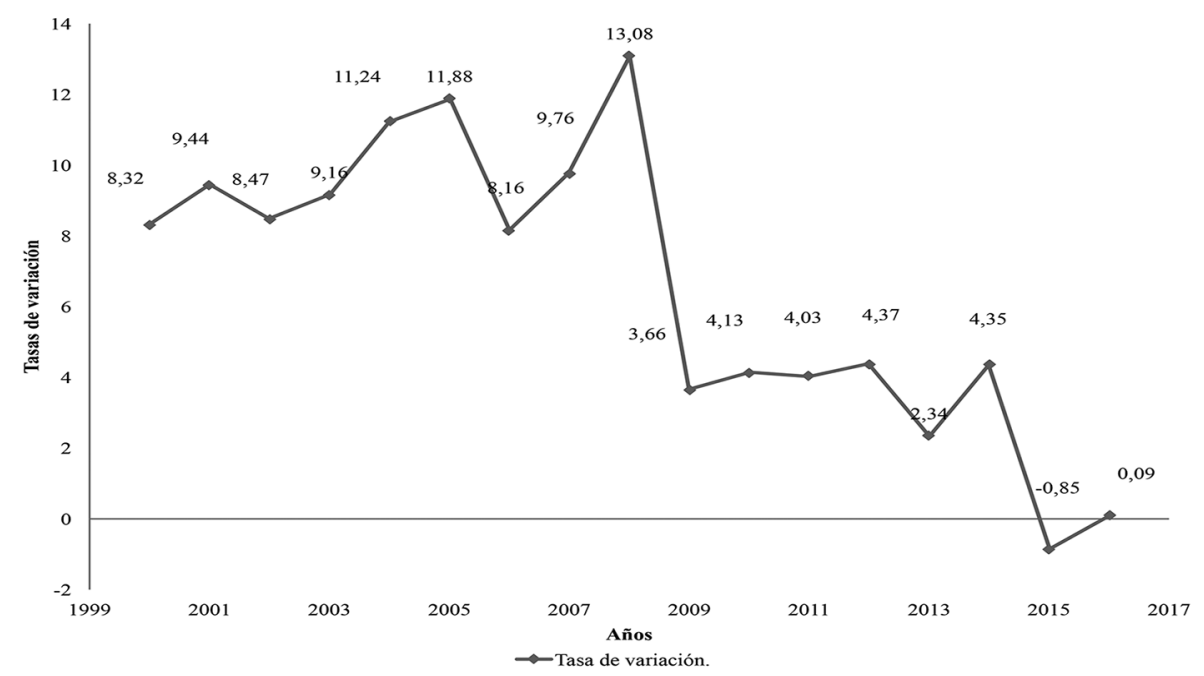

Fuente: Elaboración propia a partir de datos del BCR.

Si se observa la Figura 3, es posible determinar dos comportamientos de la variación acumulada de la inflación. Al comienzo del siglo XXI, el crecimiento de la inflación es de dos dígitos, en cambio, a partir del año 2009, es de tan solo de un dígito. Lo anterior sugiere un aumento de la capacidad de pago de la población vía menor crecimiento de la inflación. Lo anterior podría ser positivo para las relaciones económicas. Sin embargo, la Figura 2 marca el año 2009 como el inicio de un crecimiento cada vez menor de la economía, su estado negativo. Entonces, la menor inflación se contextualiza en un estado de bajo crecimiento del PIB, por lo que no se estima positiva. No se acelera el aumento de los precios. No obstante, un bajo crecimiento del PIB y un desempleo alto, como el que ocurre a partir del año 2010, señalan dificultades para que la población reciba ingresos con los cuales comprar los productos.

En síntesis, los datos anteriores sugieren un deterioro del crecimiento del PIB a partir del año 2009, cuando la producción decrece en $0.65 \%$ (Figura 2). Después de dicho año, es posible señalar un crecimiento del desempleo en aproximadamente un $3.5 \%$. A un crecimiento menor de la economía y un aumento del desempleo, se suma un sector monetario con crecimientos menores en la variación acumulada de la inflación. En cuanto a los años en los cuales se analizará la situación financiera de GN, del año 2006 al 2016, se percibe un buen entorno económico de Costa Rica entre los años 2006 y 2008, lo cual es favorable para la empresa; en cambio, para los años posteriores al 2009, se estima un contexto económico adverso para la actividad productiva de GN. 


\section{Análisis de los ingresos y utilidades netas de Grupo Nación}

El análisis financiero inicia con dos componentes fundamentales de cualquier empresa: los ingresos y las utilidades netas. Los ingresos son importantes, pues indican si la empresa genera recursos propios año a año y las utilidades netas muestran los ingresos al deducir los costos, gastos e intereses, lo cual permite apreciar cuánto de los ingresos se apropia la empresa. En este sentido, el la Figura 4 ilustra un análisis horizontal (tasas de variación) sobre los ingresos de GN.

Figura 4

INGRESOS TOTALES Y TASAS DE VARIACIÓN* POR AÑO PARA GRUPO NACIÓN, 2005-2016 (EN MILLONES DE COLONES Y PORCENTAJES)

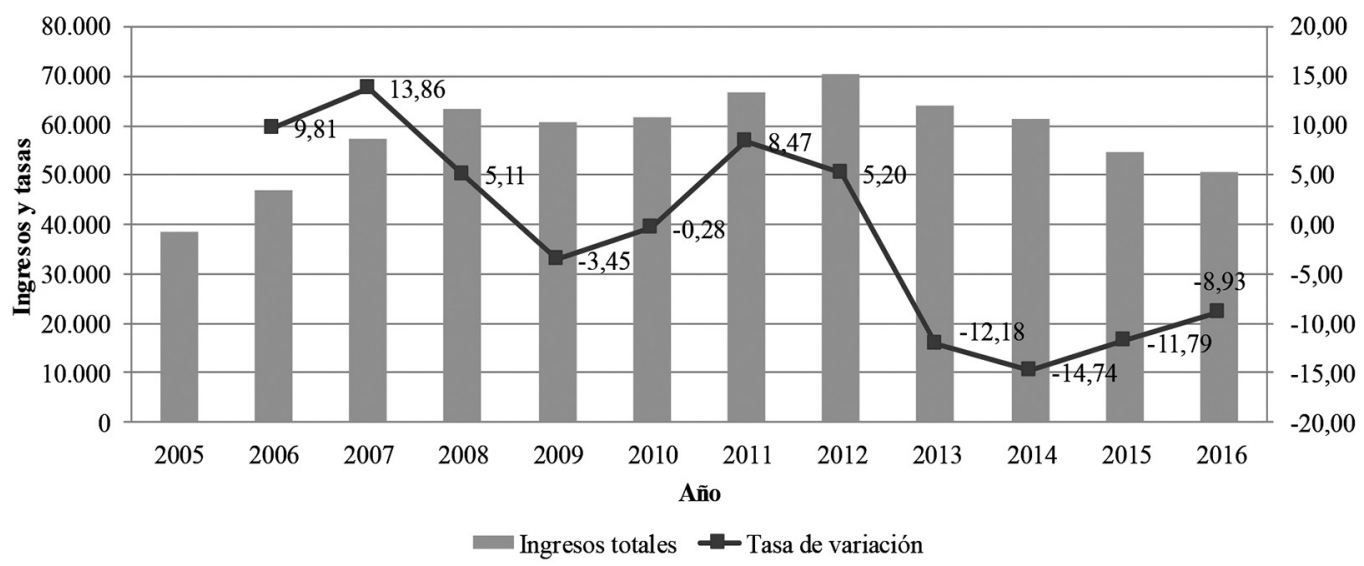

Fuente: Elaboración propia a partir de estados financieros de GN. *Variaciones con cifras deflactadas.

Como se desprende de la Figura 4, es posible advertir dos tendencias en los ingresos de GN. La primera tendencia, del año 2006 al 2012, es de crecimiento, si bien reportan dos disminuciones para los años 2009 y 2010, la dirección del comportamiento es hacia el crecimiento. El decrecimiento para el 2010 se explica por una reducción en la capacidad de pago de los ingresos de dicho año (un aumento del Índice de Precios del sector de Información y Comunicación con el cual se deflactaron las cifras). Obsérvese que en el 2009 los ingresos de GN reportan la disminución más importante para el período 2006-2012. En el año 2009, tal como muestra la Figura 2, la economía nacional muestra su peor signo, decrece. Lo anterior implica que GN vivió los embates del inicio de una ola de menores crecimientos en la economía nacional.

También, es importante señalar en esta primera tendencia que, como los ingresos inician con un monto de 38482 millones de colones y finalizan con 70550 millones, este último monto es 1.8 veces mayor que el inicial. Si se calcula una tasa de variación 
promedio anual sobre los ingresos, se obtiene un crecimiento promedio de $0.41 \%$, lo cual confirma una tendencia constante al alza. Además, es posible observar que los crecimientos en esta tendencia son cada vez menores a partir del año 2008, no alcanzan magnitudes cercanas a los dos dígitos, como en el año 2006 y 2007. Los ingresos crecen, pero cada vez a un ritmo menor.

La segunda tendencia se marca a partir del año 2013, donde los ingresos de GN tienden a disminuir cada año. Del año 2013 al 2016, los ingresos disminuyen a una tasa variación promedio anual de 10.54 \% el 2013 y el 2015 son los años que reportan mayores decrecimientos, alrededor de $13 \%$. Si en el 2012 GN tuvo ingresos por 70550 millones, el año 2016 termina con un ingreso de 50616 mil millones, 1.39 veces menor. También, nótese que los decrecimientos son de dos dígitos, lo cual indica un proceso de decrecimiento acelerado. Incluso, si se observan los crecimientos del año 2006 al 2012, únicamente en el año 2007 la variación positiva es de dos cifras. Es decir, en el período de análisis, la reducción de sus ingresos tiene un ritmo mayor al de sus crecimientos.

Entonces, los datos sugieren al menos dos tendencias: un crecimiento cada vez menor de los ingresos y una tendencia decreciente de estos. En este contexto, es importante observar la composición de los ingresos de GN (fuentes o rubros) y los componentes o rubros que aportan al decrecimiento, es decir, realizar un análisis vertical sobre los ingresos. Como sugiere la Tabla 4, el 77.51 \% de los ingresos del medio provienen de la venta de publicidad y de la circulación de sus impresos (venta). Este $77.51 \%$ representa 39234 millones de colones. Al ser la mayoría de sus ingresos, es posible confirmar que GN se ha instalado en un modelo de negocios tradicional: venta de impresos y de espacio publicitario a través de estos.

El resto de los componentes de sus ingresos conforman apenas el $22.49 \%$ del total. Durante el año 2016, los ingresos totales se redujeron un $8.93 \%$; la cuenta de publicidad

Tabla 4

INGRESOS DE GRUPO NACIÓN (EN MILLONES DE COLONES Y PORCENTAJES)

\begin{tabular}{lrrccc}
\hline Rubros & 2015 & 2016 & Proporción & Tasa de variación* & Aporte* \\
\hline Publicidad & 33364 & 29011 & 57.31 & -14.74 & -8.45 \\
Circulación & 11264 & 10223 & 20.20 & -11.01 & -2.22 \\
Servicios de impresión & 2670 & 2591 & 5.12 & -4.85 & -0.25 \\
Venta de papeles y cartulinas & 1473 & 1450 & 2.86 & -3.48 & -0.10 \\
Promociones & 791 & 460 & 0.91 & -42.98 & -0.39 \\
Medios digitales & 1822 & 1939 & 3.83 & 4.35 & 0.17 \\
Otros & 3113 & 4943 & 9.77 & 55.69 & 5.33 \\
Ingresos totales & 5497 & 50616 & 100 & -8.93 & -9.62 \\
\hline
\end{tabular}

Fuente: Elaboración propia con datos de los informes financieros de Grupo Nación. *Variación y aporte con cifras deflactadas. 
y circulación son las que más aportaron a la disminución, un $8.45 \%$ y un $2.22 \%$, respectivamente. Por tanto, son los que explican la disminución total de los ingresos. Nótese que de los 7 componentes o rubros que producen los ingresos totales, 5 de estos disminuyen. El rubro de promociones es el que más lo hace, 3 de estos rubros disminuyen más que los ingresos totales: circulación, publicidad y promociones (destacan publicidad y circulación). Los rubros que crecen, medios digitales y otros -donde está Parque Viva, centro de eventos de GN- representan una proporción pequeña de los ingresos totales, $3.83 \%$ y $9.77 \%$, respectivamente, por lo cual no logran revertir la tendencia total de los ingresos.

Ahora se realizará un análisis de las utilidades netas de la empresa. La Figura 5 tiene este objetivo. Como es posible observar, al igual que las dos tendencias de los ingresos expresadas en la Figura 4, las utilidades netas expresan dos tendencias, la primera va del año 2005 al 2012 y la segunda del año 2013 al 2016. La primera tendencia, el año 2006, marca un crecimiento importante, donde las utilidades crecen casi $500 \%$, para situarse en los miles de millones. Durante este período las utilidades promedian 3628 millones de colones y la mayoría de los años, excepto el año 2010, se encuentran por arriba del promedio. En los mejores años, 2008 y 2009, las utilidades son 1.42 y 1.27 veces mayores al promedio, respectivamente. Lo anterior sugiere una magnitud importante y una tendencia al crecimiento por parte de las utilidades.

Figura 5

UTILIDADES NETAS POR AÑO PARA GRUPO NACIÓN, 2005-2016

(EN MILLONES DE COLONES)

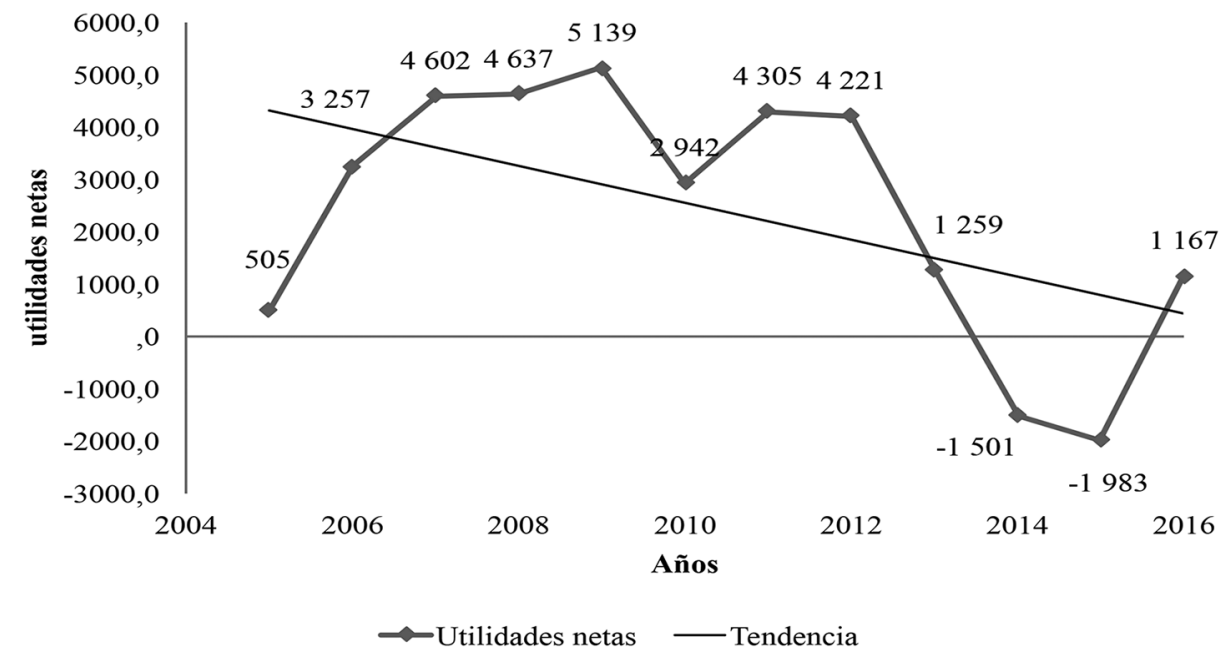

Fuente: Elaboración propia a partir del Informe Financiero GN. 
La segunda tendencia inicia con un decrecimiento en las utilidades netas. Para el año 2013, las utilidades son 3.35 veces menores a las del año 2012. Obsérvese que GN reporta para el año 2014 y 2015 dos pérdidas consecutivas en sus utilidades netas, la empresa pierde 1501 y 1983 millones de colones, respectivamente. Luego, en el año 2016, se observa una recuperación significativa, pues, para salir de pérdidas, la empresa tuvo que producir alrededor de 3628 millones en utilidades netas contra el año anterior. Es decir, produjo lo suficiente para reponer las pérdidas y obtener beneficios. Si bien hay recuperación, en esta segunda tendencia, las utilidades promedian un monto 3 veces menor al de la primera, 1212 millones.

Finalmente, en la primera tendencia, las figuras 4 y 5 señalan, para el año 2006 y 2007, un crecimiento significativo de los ingresos y las utilidades netas, el cual se mencionó en párrafos anteriores. Si bien no se cuenta con información detallada sobre este acontecimiento, Muñoz analiza los estados financieros de GN para el período comprendido entre el año 1998 y 2002 y permite, preliminarmente, contextualizar estos crecimientos en el marco de la ampliación de las actividades productivas de GN en Centroamérica. Según Muñoz, dichas actividades amplían los rendimientos en los ingresos y utilidades, las cuales, vale decir, cierran alrededor del año 2009 (La Nación S. A. y Subsidiarias, 2010).

Para la segunda tendencia, los datos anteriores sugieren que el correlato de la disminución en los ingresos de GN es el decrecimiento de sus utilidades netas, al punto de producir pérdidas dos años consecutivos. Nótese que las disminuciones son más significativas en dichas utilidades, pues los ingresos cierran con un monto 1.39 veces menor al inicial, en cambio, las utilidades representan un monto 3 veces menor. Si bien las utilidades muestran una recuperación para el año 2016, los ingresos para ese año cumplen cuatros años consecutivos de disminución. Lo anterior plantea la interrogante de si el aumento de sus utilidades es sostenible a largo plazo.

\section{Análisis con razones financieras}

En esta sección se realizará el análisis sobre el balance general y los estados de resultados de GN a través de razones financieras, el cual se hará en el corto y largo plazo. Para el análisis del corto plazo se utilizarán las razones de liquidez RC y RPA y la razón de deuda REC. Para el largo plazo se utilizará la razón de actividad RI y la RI en días, la razón de deuda RET y la RPP; además, las razones de rentabilidad MUN, rotación de activos totales RAT y RSI. ${ }^{2}$

\section{Análisis en el corto plazo: Liquidez y endeudamiento}

La liquidez o solvencia para GN se ilustra en la Figura 6. Como es posible observar, en cuanto a la $\mathrm{RC}$, pocas veces la empresa se encuentra por arriba del parámetro idóneo de 2.5 veces. Sin embargo, es posible apreciar una liquidez solvente, pues la 
razón siempre se encuentra por arriba de 1, lo cual indica la capacidad de la empresa de pagar sus deudas con recursos propios. Si se valora su RC más bajo, en el año 2008, se puede observar que cubre sus pasivos sin problemas. En dicho año, por cada colón de deuda, GN tiene 1.51 colones de activos o, lo que es lo mismo, los activos cubren 1.51 veces a los pasivos. Si la empresa ese año pagara sus deudas de corto plazo con sus recursos del mismo plazo, tendría un colchón de liquidez de 0.51 colones por cada colón adeudado.

Figura 6

RAZÓN CIRCULANTE Y PRUEBA ÁCIDA POR AÑO PARA GRUPO NACIÓN, 2005-2016 (EN NÚMERO DE VECES)

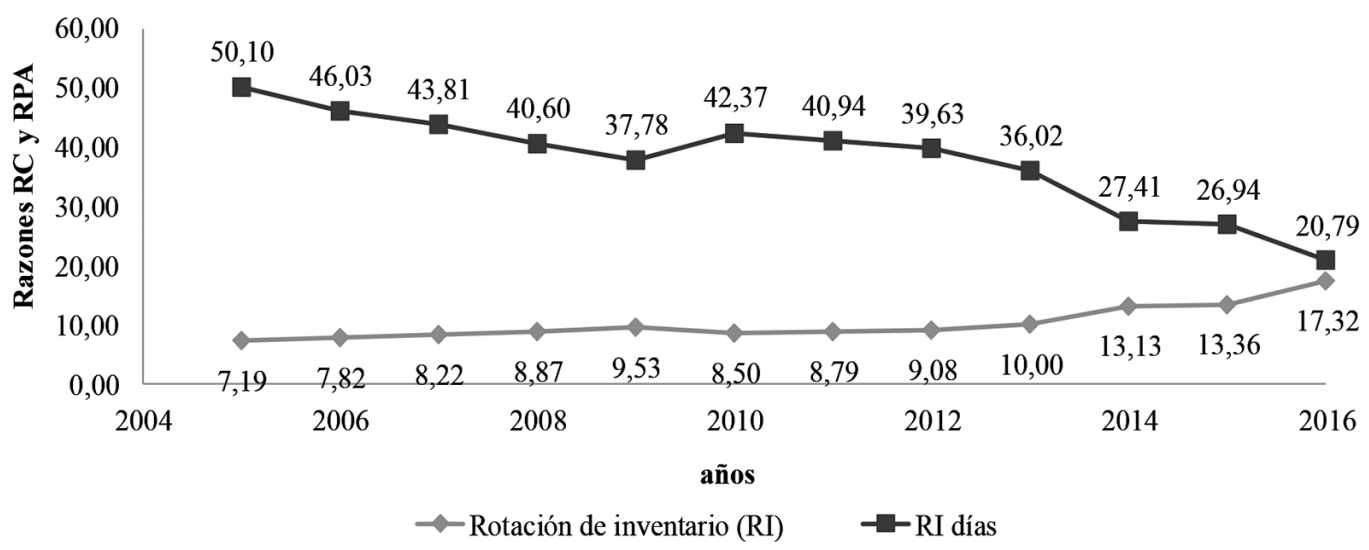

Fuente: Elaboración propia a partir del Informe Financiero GN.

Si se observa la RPA, las diferencias con la RC no son muy grandes. También se encuentra por arriba de uno. Además, dicha razón se encuentra muy cercana o por arriba del parámetro idóneo de 1.5 veces. Nótese que tanto la RC y la RPA tienen una tendencia a aumentar y, por tanto, a mostrar cada vez más solvencia o liquidez. Destaca el año 2014, donde, de acuerdo con la RC, GN tiene 4.54 colones por cada colón de deuda y, de acuerdo con la RPA, por cada colón de deuda tiene 4.19 colones en activos. Es decir, sus activos cubren en más de 4 veces sus pasivos. Incluso, los años en los cuales pierde utilidades, 2014 y 2015, GN muestra un margen positivo en cuanto a su liquidez en el corto plazo.

Además, se puede observar en la Figura 6 cómo ambas razones de liquidez aumentan de manera significativa a partir del año 2014. Esto se explica porque los activos corrientes crecen un $78.46 \%$, mientras los pasivos corrientes disminuyen un $16.78 \%$. El aumento significativo en la magnitud de los activos corrientes se debe a dos inversiones realizadas por GN durante el año 2013 y 2014. Las cuales responden, por una 
parte, a la producción de un espacio físico (un edificio) para la integración de las salas de redacción de sus medios de comunicación colectiva y, por otra, a la compra del Autódromo La Guácima para convertirlo en un centro de eventos (Carazo), conocido ahora como Parque Viva. Entonces, el aumento de la liquidez en el corto plazo se debe a estas inversiones de largo plazo.

El nivel de endeudamiento en el corto plazo se presenta en la Figura 7. Para el período 2005-2008, se observa que las deudas representan una cuarta parte de los activos totales, para luego mostrar una tendencia a la reducción; el año 2016 finaliza con un margen de deuda de tan solo 1 dígito, lo cual implica una reducción significativa de las deudas. $\mathrm{Al}$ igual que las razones de liquidez, las inversiones de GN tienen implicaciones para su nivel de deudas. Recuérdese que la razón de endeudamiento corriente se calcula entre el pasivo corriente y el activo total o de largo plazo. Para el año 2014, los activos totales crecieron $12.91 \%$, mientras los pasivos de corto plazo disminuyeron $16.78 \%$, como se anotó anteriormente. Cabe destacar que esta inversión en activos es la más importante en los 12 años en análisis. Por lo tanto, la reducción en el nivel de deudas a partir del año 2014 se explica por las inversiones antes mencionadas (hacen crecer el activo total, denominador de la REC) y la reducción del pasivo de corto plazo o corriente (numerador de la REC).

Figura 7

RAZÓN ENDEUDAMIENTO CORRIENTE POR AÑO PARA GRUPO NACIÓN, 2005-2016

(EN PORCENTAJES)

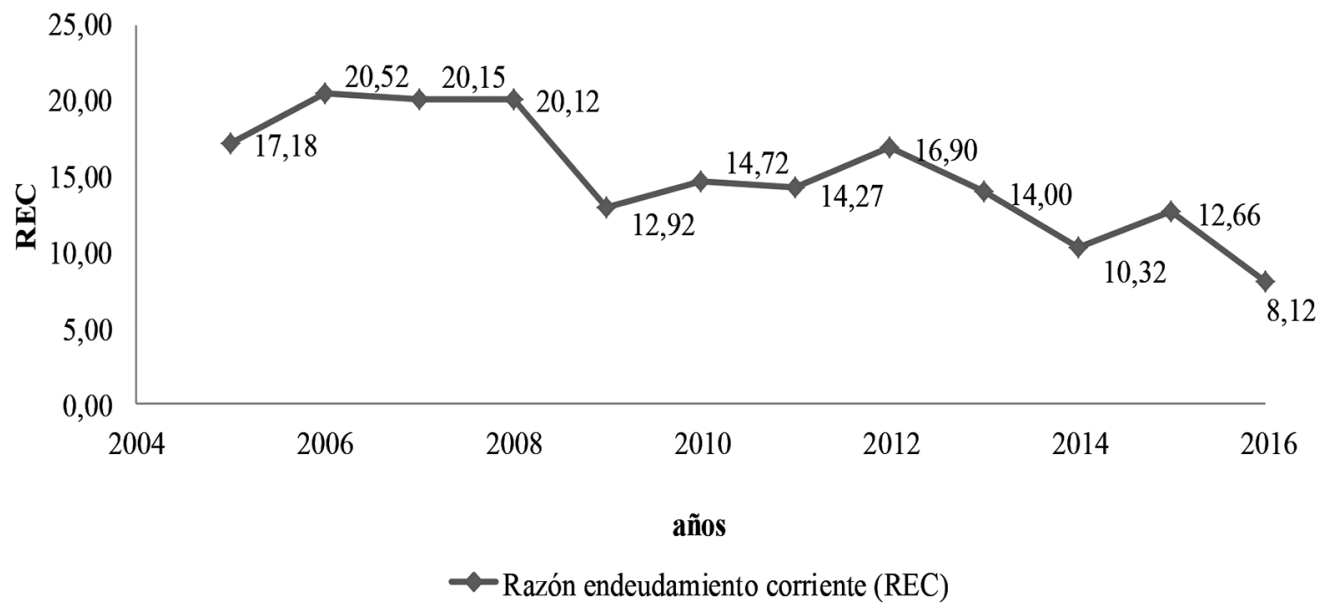

Fuente: Elaboración propia con datos del Informe Financiero GN.

Por último, para el corto plazo, en los 12 años en análisis, los datos expresados en las figuras 6 y 7 muestran una posición positiva de la liquidez y el endeudamiento 
para GN. Las razones de liquidez siempre se encuentran por arriba de uno (sus recursos propios pueden cubrir sus deudas) y los activos financiados con deuda tienen una tendencia a la disminución. Sin embargo, debe tomarse en cuenta el papel de las inversiones en activos totales, con implicaciones significativas para los activos corrientes, en tal posición positiva y evaluar su significado para el largo plazo. Lo anterior, para el caso de las deudas, se evaluará en el siguiente apartado.

\section{Análisis en el largo plazo: Actividad, endeudamiento y rentabilidad}

Como se señaló anteriormente, las RI y la RI en días expresan la eficiencia de la empresa en su actividad productiva (comprar, vender y generar ingresos y utilidades), al indicar la velocidad con la que rota su inventario, y, por tanto, la velocidad de las ventas (generación de recursos). Ahora bien, a partir de la Figura 8 se realizará el análisis de ambas razones para GN.

Figura 8

ROTACIÓN DE INVENTARIO POR AÑOS PARA GRUPO NACIÓN, 2005-2016

(EN NÚMERO DE VECES Y DE DÍAS)

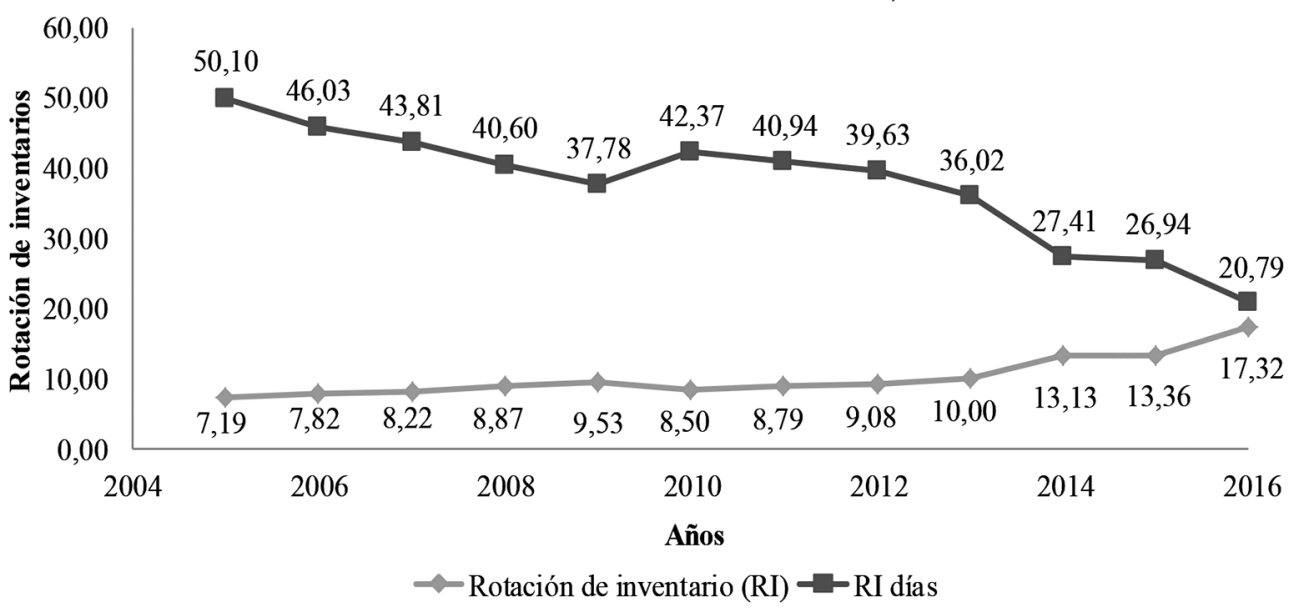

Fuente: Elaboración propia a partir del Informe Financiero GN.

En la Figura 8 es posible percibir una tendencia al incremento de la RI y una disminución de la RI en días, lo cual sugiere eficiencia en el uso de recursos por parte de GN, pues cada vez compra, vende y genera ingresos en un tiempo menor, o, lo que es lo mismo, su inventario rota cada vez más rápido. Como la rotación de inventario se calcula con los costos de ventas y estos están ligados con los ingresos (producir ingresos tiene costos), es necesario analizar dicha eficiencia en el marco de las dos tendencias detectadas en los ingresos. 
La primera tendencia en los ingresos comprende los años del 2005 al 2012 y registra un aumento cada vez menor de estos. En este intervalo, obsérvese que la RI aumenta y la RI en días disminuye. De acuerdo con la RI, en el año 2005, GN genera recursos 7.19 veces al año, en promedio cada 50 días (RI días). Para el año 2012, la RI aumenta a 9.08 veces, lo cual indica una mayor rotación del inventario al año y, por lo tanto, un período cada vez menor en el cual se producen recursos, en promedio cada 39 días (RI en días). Lo anterior en un contexto de crecimiento de ingresos, aunque sean cada vez menores, se estima positivo, pues se observan aumentos en los ingresos y un período más corto en el cual se producen.

La segunda tendencia en los ingresos comprende los años del 2013 al 2016 y registra una disminución de los ingresos para cada año. En este intervalo, se intensifica el aumento de la RI y, por tanto, la diminución promedio de los días en los cuales GN rota su inventario, lo cual implica una generación cada vez más rápida de recursos. En un contexto de bajos ingresos, es necesario valor la magnitud del inventario, denominador de la RI. Para el período 2005-2012, el inventario promedio ronda los 5157 millones de colones, en cambio, para el período 2013-2016 promedia 3378 millones de colones, 1.5 veces menos. En ese sentido, el año 2016 reporta el menor inventario, con un monto 1981 millones de colones.

Los datos anteriores sugieren que, para los años comprendidos entre el año 2013 y 2016, si bien GN tiende a mejor su eficiencia en ventas, pues genera recursos en un tiempo cada vez menor, dada la reducción del inventario, es posible señalar que cada vez vende menos, lo cual, en el contexto de la segunda tendencia de sus ingresos (reducción), se estima negativo.

\section{Razones de endeudamiento}

Con el objetivo de analizar el endeudamiento de GN en el largo plazo, la Figura 9 reúne su porcentaje de activos financiados con deuda, es decir, la RET. Recuérdese que para este caso existen parámetros sobre el nivel de deudas, estipulados en la Figura 2. De acuerdo con la Figura 2, los primeros 3 años del período expresan un exceso de deudas. Luego, para los años comprendidos entre el 2008 y el 2013, GN se establece en un margen de endeudamiento sostenible, para después aumentar su nivel de deuda a partir del año 2014. Como se comentará a continuación. 
Figura 9

RAZÓN ENDEUDAMIENTO TOTAL POR AÑO PARA GN, 2005-2016

(EN PORCENTAJES)

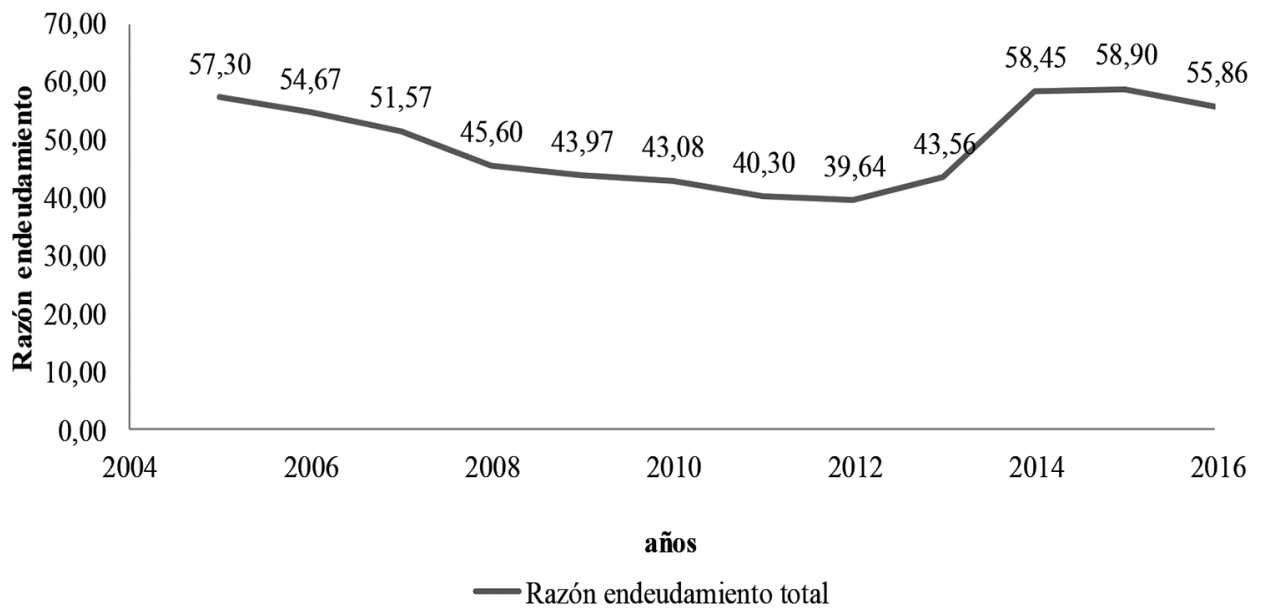

Fuente: Elaboración propia a partir del Informe Financiero GN.

Como se advierte en la Figura 9, para el año 2014, el porcentaje de activos financiado con deuda crece prácticamente en un $15 \%$, lo cual representa el aumento más significativo en los 12 años en análisis. Obsérvese que este aumento en las deudas puede partir del año 2013, cuando las deudas aumentan alrededor de un $5 \%$. Este es el aumento más importante en el intervalo de años en los cuales las deudas de GN se encuentran en un estado sostenible. Así, con el ascenso de las deudas, los últimos 3 años expresan una RET en estado excesivo.

Como se mencionó anteriormente, en los años 2013 y 2014, GN realiza dos inversiones, la producción de un edificio y la compra de un centro de eventos, que aumentan los activos totales, pero no los pasivos corrientes. En el largo plazo, estas inversiones tienen otro resultado para los pasivos. Mientras los activos totales crecen un $12.09 \%$, los pasivos totales lo hacen un $51.58 \%$. Lo anterior sugiere que las inversiones realizadas por GN se asientan en las deudas de largo plazo; estas explican el margen en el exceso de deudas para los años 2014, 2015 y 2016.

Ahora bien, un aspecto a analizar en el endeudamiento es la relación entre el patrimonio y la deuda, para observar si GN tiene un margen de protección proporcionado por sus propietarios o accionistas. Para realizar dicho análisis, la Figura 10 contiene la RPP. Recuérdese que cuanto más baja la razón, mayor capacidad de la empresa para pagar sus deudas con su patrimonio. 
Figura 10

PATRIMONIO Y RAZÓN PASIVO-PATRIMONIO POR AÑO PARA GRUPO NACIÓN

(EN MILLONES DE COLONES Y EN NÚMERO DE VECES)

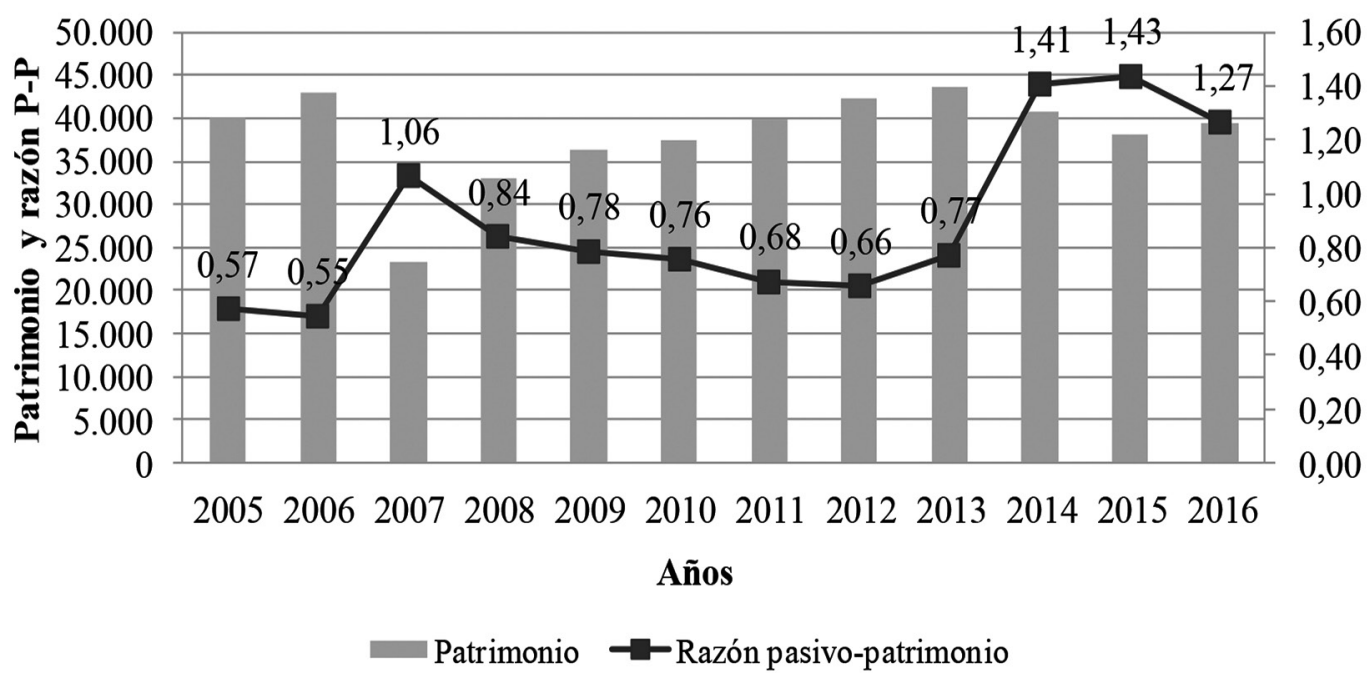

Fuente: Elaboración propia a partir del Informe Financiero GN.

Como se desprende de la Figura 10, del año 2005 al 2012, con excepción del año 2007, GN tiene posibilidades de pagar sus deudas con su patrimonio, pues siempre se encuentra por debajo de 1. Tómese como ejemplo el año 2005 para la interpretación de la RPP. En dicho año, por cada colón de patrimonio, GN tiene 0.57 colones de deuda. Si se resta el colón de patrimonio con los 0.57 colones de deuda, la empresa tiene un margen de protección de 0.43 colones otorgado por sus accionistas; es decir, el patrimonio es más grande que los pasivos. Además, en este intervalo de tiempo, con la salvedad del año 2007, el patrimonio tiene una tendencia a aumentar. Con la cual se refuerza dicho margen de protección sobre las deudas.

En cambio, para los años siguientes, del año 2014 en adelante, el margen de protección de la empresa desaparece y el patrimonio tiende a disminuir. Para dicho año, la RPP indica que, por cada colón de patrimonio, la empresa tiene 1.41 colones de deuda; es decir, los pasivos cubren 1.41 veces al patrimonio. Lo anterior significa que, si GN cerrara operaciones ese año, no podría pagar sus deudas con su patrimonio. Estos datos sugieren que esta empresa se encuentra con un nivel de deudas que excede los recursos aportados por sus accionistas. Además, mientras sus deudas aumentan, su patrimonio disminuye; esto podría sugerir que la empresa está utilizando su patrimonio para actividades de operación. 


\section{Razones de rentabilidad}

Es el momento de evaluar el resultado de la liquidez, la administración de los activos y las deudas, lo cual se realizará por medio de las razones de rentabilidad. Se iniciará el análisis con el MUN, el cual muestra el nivel de ingresos que se apropia la empresa después de deducir costos, gastos, intereses e impuestos. Luego se realizará la razón $\mathrm{RAT}$ y, por último, la razón RSI.

Figura 11

MARGEN DE UTILIDAD NETA POR AÑO PARA GRUPO NACIÓN, 2015-2016

(EN PORCENTAJE)

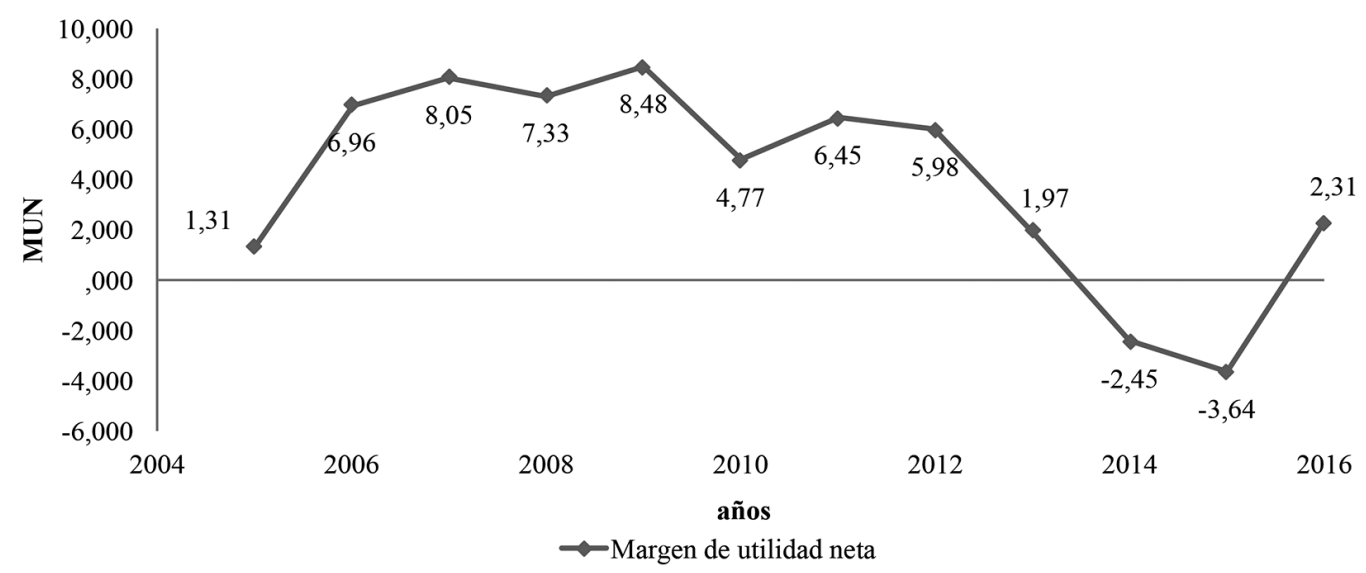

Fuente: Elaboración propia a partir del Informe Financiero GN.

Los datos expuestos en la Figura 11 deben interpretarse a partir de los parámetros presentados en la Tabla 3. De acuerdo con estos, para el año 2005, puede observarse que GN inicia el período de análisis con un MUN de $1.31 \%$, este margen es de rentabilidad baja. El año siguiente se recupera en prácticamente un $6 \%$, estableciendo un margen de rentabilidad estable para los años comprendidos entre el año 2006 y el 2012. En el mismo intervalo de tiempo que la segunda tendencia de los ingresos, el período 2013-2016, el MUN expresa rentabilidades bajas e incluso negativas. Esto se debe a la tendencia en la reducción de los ingresos y de las utilidades netas.

En el apartado de análisis de endeudamiento, se observó un incremento en los activos totales y los pasivos totales, dadas las inversiones en infraestructura y la adquisición de un centro de eventos. La RAT mostrará los colones de ingresos que producen dicha inversión y los activos totales en general. 
Figura 12

ROTACIÓN ACTIVOS TOTALES POR AÑO PARA GRUPO NACIÓN, 2005-2016

(EN NÚMERO DE VECES)

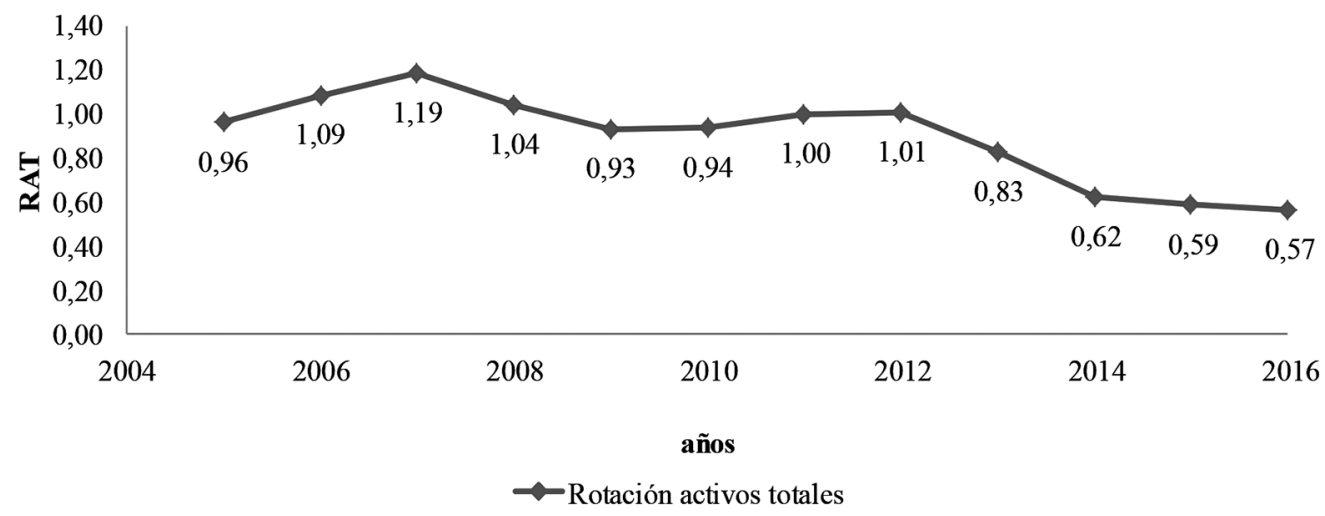

Fuente: Elaboración propia a partir del Informe Financiero GN.

Como se observa en la Figura 12, durante los primeros 8 años del período de análisis, prácticamente, cada colón de activo produjo un colón de ingresos. El año 2007 fue el periodo más productivo de los activos de GN, por cada colón de activos, se produjeron 1.19 colones de ingresos. Sin embargo, la tendencia cambia para el periodo comprendido entre el año 2013 y el año 2016, los ingresos producidos por los activos tienden a disminuir.

En el año 2014 se produjo el crecimiento más importante de los activos totales, en el período de análisis, como se ha mencionado anteriormente. Sin embargo, como se desprende de la Figura 12, los activos reportados a ese año generan menos recursos que el año anterior. Incluso, para el año 2016, se muestra el peor rendimiento de los activos en todo el período. Por cada colón de activos, se producen 0.57 colones de ingresos. En un contexto de reducción de ingresos y utilidades netas, los datos anteriores sugieren que las inversiones realizadas por GN no mejoran los ingresos producidos en un margen que compense la tendencia a la disminución de sus ingresos.

Finalmente, se realizará la razón RSI y se comparará con el promedio en años de la tasa básica pasiva calculada por el Banco Central de Costa Rica. Se considera que el costo de oportunidad que permite dicha tasa puede valorarse conjuntamente con las utilidades netas, para saber si es mejor tener el dinero invertido por GN en activos o en un banco generando intereses, al menos desde un punto de vista económico, pues los productos de GN, como se ha señalado en este artículo, también le permiten a la empresa hacer política. 
Figura 13

RENDIMIENTO SOBRE LA INVERSIÓN POR AÑO PARA GRUPO NACIÓN

Y TASA BÁSICA PASIVA, 2005-2016

(EN PORCENTAJES)

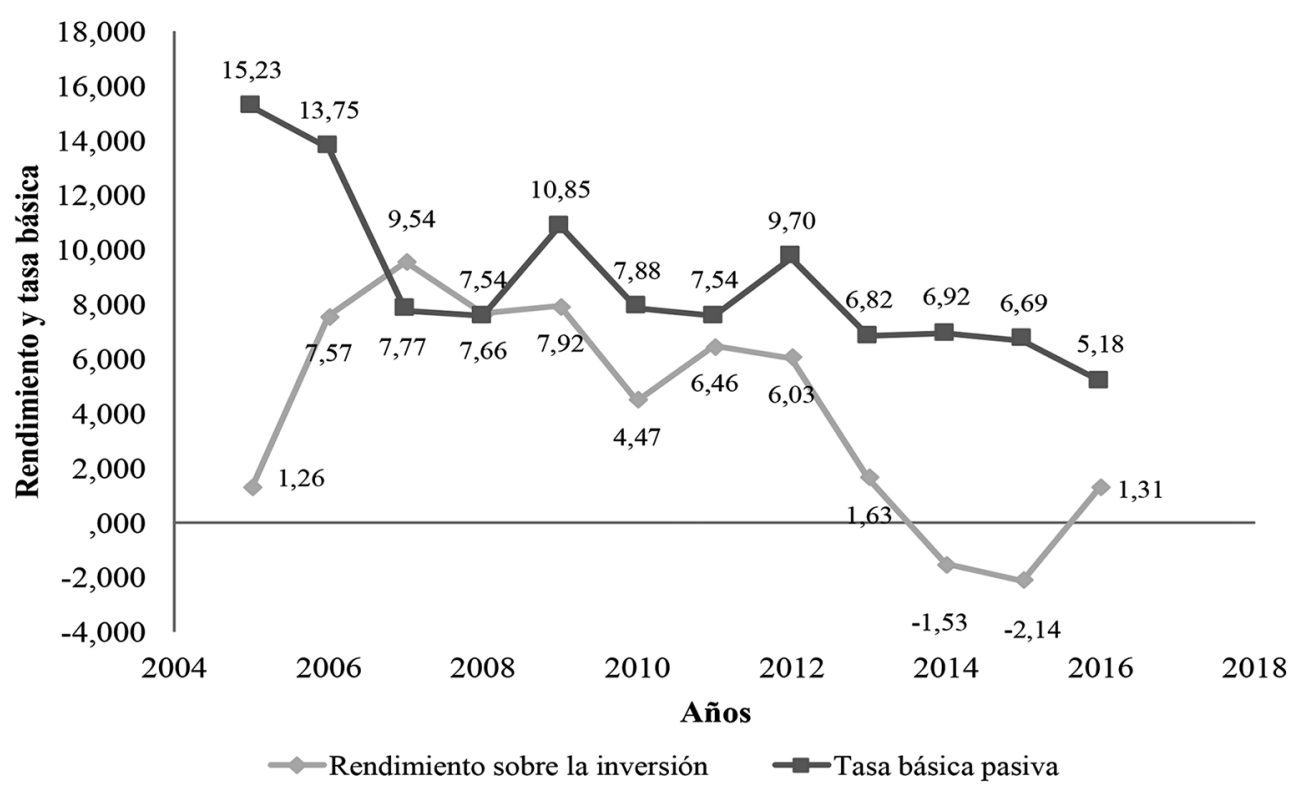

Fuente: Elaboración propia a partir del Informe Financiero GN.

La Figura 13 muestra que los activos de GN producen márgenes de rendimiento inferiores a la tasa básica pasiva para casi todos los años en estudio; sin embargo, la diferencia no es muy alta. Para el período 2005-2012, los rendimientos de la empresa son similares a los de tener sus activos en un banco. Si se considera el comportamiento de los ingresos y las utilidades, cuyo comportamiento es creciente, se estiman márgenes de rendimiento positivos. Por ejemplo, para el año 2010, donde se expresa la menor RSI, GN se apropia del $4.47 \%$ de sus activos, el equivalente 2942 millones de colones en utilidades netas.

Sin embargo, a partir del año 2013, se observa una tendencia a la disminución por parte de la RSI, la cual la aleja considerablemente de la tasa básica, pese a que esta también disminuye. Lo anterior sugiere que los activos de GN generan cada vez menos utilidades. Si en el año 2012, el $6.03 \%$ de los activos se convertía en utilidades netas, para el año 2016, tan solo el $1.31 \%$ se produce como utilidades. Todo esto sugiere que las inversiones realizas por la empresa a partir del año 2013 y 2014, donde los activos totales tienen el mayor crecimiento del período en estudio, generan rendimientos cada vez menores. Por último, si se considera que las utilidades netas son negativas en los 
años 2014 y 2015, a partir del 2013, GN generaría mayores rendimientos si sus activos totales estuvieran en un banco ganando intereses.

\section{Balance final}

Los datos expuestos en este artículo sugieren de manera preliminar, para la industria de medios de comunicación impresos de Costa Rica, un deterioro inicial en el comportamiento de los ingresos por venta de espacio publicitario y una reducción de la audiencia de periódicos, mientras el consumo de internet aumenta, lo cual podría sugerir una situación crítica para el modelo de negocios de la industria. En este contexto, de los informes financieros de GN se constata una reducción en sus rendimientos financieros. Los ingresos de la empresa disminuyen cada año a partir del 2013. Incluso, esta disminución se tradujo en pérdidas en sus utilidades netas en los años 2014 y 2015, 1501 millones de colones y 1983 millones, respectivamente. Aunado a lo anterior, la situación económica del país muestra sus peores indicadores. El PIB y el desempleo no logran alcanzar sus niveles anteriores a la crisis económica del año 2009, se viven o sufren aproximadamente 10 años de recesión económica, lo cual es desfavorable para GN y el resto de industrias instaladas en Costa Rica.

Sobre la situación financiera de GN, es posible percibir dos tendencias en su situación financiera: una que abarca los años comprendidos entre el 2005 y 2012, en la cual los ingresos de la empresa tienen una tendencia a crecer cada vez menos. Una segunda que cubre el período entre el año 2013 y el 2016, en el cual la disminución de sus ingresos marca la tendencia. Bajo estas tendencias, el corto plazo muestra indicadores favorables para la empresa: la solvencia o liquidez económica muestra que por cada colón de pasivos existen aproximadamente cuatro colones de activos. Por su parte, las deudas pasan de dos dígitos a un digito, lo cual sugiere una disminución de sus activos comprometidos a corto plazo.

Sin embargo, el largo plazo no es favorable para la empresa. La razón de actividad rotación de inventario, la magnitud del inventario y la disminución de los ingresos de la empresa muestran que GN genera ingresos en menos tiempo, porque vende cada vez menos periódicos y recibe menos ingresos por publicidad. Además, sus deudas en largo plazo son excesivas. El año 2016 cierra con el $55.86 \%$ de sus activos comprometidos. Las inversiones realizadas por GN durante los años 2013 y 2014, un edificio y la adquisición de un centro de eventos, explican este exceso de deudas.

Pese a esta inversión, los indicadores de rentabilidad señalan un rendimiento a la baja. El margen de utilidad neta muestra que GN se apropia de un margen cada vez más pequeño de los ingresos que produce. Si en el año 2006 se apropiaba del $6.96 \%$ de sus ingresos, 10 años más tarde se apropia únicamente del $2.31 \%$. La rotación de activos totales, que permite evaluar los ingresos producidos por los activos, muestra que las inversiones realizadas por GN no lograron mejorar sus rendimientos: durante 
la mayor parte del período de análisis, cada colón invertido en activos produjo un colón de ingresos, situación que cambia a partir del año 2013, donde se establece una tendencia en la cual cada colón invertido en activos produce ahora menos de un colón. Es decir, los activos producen menos ingresos. El rendimiento sobre la inversión, cantidad de activos que se transforman en utilidades netas, expresa esa misma tendencia, los activos producen cada vez menos utilidades: en el año 2006 produjeron $7.57 \%$; en cambio, 10 años después, tan solo $1.31 \%$.

En síntesis, según los estados financieros de GN, sus ingresos y utilidades netas tienen una tendencia a la disminución, su inventario es cada vez menor, su estado de deudas es excesivo y sus rendimientos sobre los activos y los ingresos muestra un rendimiento bajo. Además, el exceso de deudas y la baja rentabilidad han comprometido el patrimonio de la empresa, a tal punto que ha disminuido y no está en la capacidad de cubrir los compromisos financieros de la empresa. Todo lo anterior sugiere una situación crítica en el modelo de negocios de GN. En este contexto, cabe preguntarse cómo hará para mantener su hegemonía económica y política.

\section{Notas}

1 Este análisis se basa en la tesis para optar por el grado de máster en Comunicación y Desarrollo de la Universidad de Costa Rica titulada "La Teja, enunciados, discursos y modos de recepción".

Para facilitar la compresión del artículo se agregará de nuevo lo que significa cada abreviatura. Razones de liquidez: $\mathrm{RC}=$ razón circulante y $\mathrm{RPA}=$ razón prueba ácida; razones de endeudamiento: $\mathrm{REC}$ = la razón endeudamiento corriente, $\mathrm{RET}$ = razón endeudamiento total y $\mathrm{RPP}$ = razón pasivo-patrimonio; las razones de rendimiento o rentabilidad: $\mathrm{MUN}$ = margen de utilidad neta, $\mathrm{RAT}$ = rotación de activos totales; y RSI = rendimiento sobre la inversión.

\section{Bibliografía}

Adorno, Theodor y Horkheimer Max. La industria de la cultura: Ilustración como engaño de las masas. Sociedad y comunicación de masas. Eds. J. Curran, M. Guverick y J. Woollacot. México: Fondo de cultura económica, 1981. 393-432.

Banco Central de Costa Rica. Banco Central de Costa Rica. s. f. Recuperado de https://www. bccr.fi.cr/seccion-indicadores-economicos/indicadores-econ\%C3\%B3micos.

Carazo, Carolina. Periodistas y salas de redacción en Costa Rica frente a los retos del siglo XXI. San José, Editorial de la Universidad de Costa Rica, 2015.

Chamorro, Carlos. Estudio sobre el poder de la prensa: Entre el mercado y el Estado. Segundo Informe sobre Desarrollo Humano en Centroamérica y Panamá, 2002.

Ferris, José. La triple crisis de los medios de comunicación. Boletín de Estudios Económicos, 67.207(2012): 533-548.

Fournier-Pereira, Marisol. Persuasión y discurso. Análisis comparativo en prensa nacional en torno a noticias sobre el Tratado de Libre Comercio (Tesis de licenciatura). Universidad de Costa Rica, 2009. 
La Nación S. A. y Subsidiarias. Estados Financieros Consolidados 30 de septiembre del 2006 y 2005. San José: Autor, 2006.

La Nación S. A. y Subsidiarias. Estados Financieros Consolidados 30 de septiembre del 2007 y 2006. San José: Autor, 2007.

La Nación S. A. y Subsidiarias. Estados Financieros Consolidados 30 de septiembre del 2008 y 2007. San José: Autor, 2008.

La Nación S. A. y Subsidiarias. Estados Financieros Consolidados 30 de septiembre del 2009 y 2008. San José: Autor, 2009.

La Nación S. A. y Subsidiarias. Estados Financieros Consolidados 30 de septiembre del 2010 y 2009. San José: Autor, 2010.

La Nación S. A. y Subsidiarias. Estados Financieros Consolidados 30 de septiembre del 2011 y 2010. San José: Autor, 2011.

La Nación S. A. y Subsidiarias. Estados Financieros Consolidados 30 de septiembre del 2012 y 2011. San José: Autor, 2012.

La Nación S. A. y Subsidiarias. Estados Financieros Consolidados 30 de septiembre del 2012 y 2011. San José: Autor, 2012.

La Nación S. A. y Subsidiarias. Estados Financieros Consolidados 30 de septiembre del 2013 y 2012. San José: Autor, 2013.

La Nación S. A. y Subsidiarias. Estados Financieros Consolidados 30 de septiembre del 2014 y 2013. San José: Autor, 2014.

La Nación S. A. y Subsidiarias. Estados Financieros Consolidados 30 de septiembre del 2015 y 2014. San José: Autor, 2015.

La Nación S. A. y Subsidiarias. Estados Financieros Consolidados 30 de septiembre del 2016 y 2015. San José: Autor, 2016.

Manghi, Paul. La alegría se apaga en las redacciones brasileñas. Media-tics: Información y Comunicación en la Era Digital, 02 Mar. 2015. Recuperado de https://www.media-tics. com/noticia/5368/e-latam/la-alegria-se-apaga-en-las-redacciones-brasilenas.html

Martín Cañas, Kattia. La tiranía de los medios de comunicación: un análisis necesario. Revista de Ciencias Sociales, 4.106(2005): 83-89.

Martínez, Matías. La crisis de los grandes periódicos. Infoamerican Commucation, 2(2010): 139-148.

Mastrini, Guillermo y Martín Becerra. Los monopolios de la verdad: Descifrando la estructura y concentración de los medios en Centroamérica y República Dominicana. Buenos Aires, Prometeo Libros, 2009.

Mastrini, Guillermo. Economía Política de la Comunicación e Industrias Culturales: apuntes sobre su vigencia. Revista Internacional de Comunicación y Desarrollo, 5(2017): 139-148.

Meoño, Mario y Daisy Jara. Análisis financiero: corto, mediano y largo plazo. Tomo II. Cartago, Editorial Tecnológica de Costa Rica, 2014.

Muñoz, Gustavo. Análisis financiero de La Nación y subsidiarias y su relación con el comportamiento del precio de mercado de sus acciones comunes durante el período 1998-2002 (Tesis de maestría). Universidad de Costa Rica, 2003.

Prior, Markus. From Choice to High Choice: The Impact of Cable television and Internet on News Exposure, Political Knowledge, and Turnout. Post-broadcasting democracy: How media choice increases inequality in political involvement and polarizes elections. New York: Cambridge University Press, 2007. 
Ramírez, Lorenzo. ¿Entonces qué mi rey? La Teja en Contexto electoral. Costa Rica: coyuntura electoral y medios de comunicación: elecciones 2014: memoria. San José: CICOM, 2014. 118-129.

Robles, Francisco y Koen Voorend. Los dueños de la palabra en Costa Rica en un contexto de reforma neoliberal. Revista Rupturas 1-2(2012): 144-161.

Robles, Francisco. Élites en El Salvador: cambios y continuidades. Anuario de Estudios Centroamericanos 43(2017): 99-124.

Sandoval, Carlos. Centroamérica desgarrada: Demandas y expectativas de jóvenes residentes en comunidades empobrecidas. Presentación inédita, sin publicar, 2018.

Sandoval, Carlos. Otros Amenazantes: Los nicaragüenses y la formación de identidades nacionales en Costa Rica. San José: Editorial Universidad de Costa Rica, 2002.

Sandoval, Carlos. Vísperas del Referéndum: la posición de los medios. Revista Envío, UCA Nicaragua, 306(2007).

Segovia, Alexander. La influencia de los grupos de poder económico en América Central. Integración real y grupos de poder económico en Centroamérica: implicaciones para el desarrollo y la democracia en la región. San José, Fundación Friedrich Ebert, 2005.

Siles, Ignacio y Pablo J. Boczkowski. Making sense of the newspaper crisis: A critical assessment of existing research and an agenda for the future work. New \& Society, 14.8(2012): 1375-1392.

Superintendencia de Telecomunicaciones. Estadísticas del sector de telecomunicaciones. Costa Rica. 2015. San José: Autor, 2016.

Thompson, John B. La nueva visibilidad. PAPERS Revista de sociología, 78.840(2005): 11-29.

Villamil, Jenaro. "Tarde y a la baja en publicidad y audiencias, Televisa pretende competir en el mercado de streaming". En Semanario Proceso, 4 de marzo de 2016. Recuperado de http://www.proceso.com.mx/432359/tarde-a-la-baja-en-publicidad-audiencias-televisa-pretende-competir-en-mercado-streaming

Villamil, Jenaro. “Televisa se desmorona y Azcárraga se repliega". En Semanario Proceso, 28 de octubre de 2017. Recuperado de http://www.proceso.com.mx/509111/televisa-sedesmorona-azcarraga-se-repliega

Wong, Ricardo. Módulo de análisis financiero. Manuscrito inédito.

Lorenzo Ramírez Cardoza. Centroamericano-caribeño con nacionalidad costarricense. Bachiller en economía por la Universidad Nacional de Costa Rica. Egresado de la maestría en Comunicación y Desarrollo de la Universidad de Costa Rica. Se desempeña como profesor universitario.

Contacto: 1.ramirez.08@gmail.com

ORCID: 0000-0001-6827-2289 
